\title{
EDITORIAL 22.1 - Sobre as Diretrizes Curriculares Nacionais para os cursos de graduação em Psicologia
}

\author{
Marilene Proença Rebello de Souza1', https://orcid.org/0000-0002-8297-5674 \\ Marilda Gonçalves Dias Facci², https://orcid.org/0000-0001-7443-490X \\ Silvia Maria Cintra da Silva ${ }^{3}$, https://orcid.org/0000-0003-0834-5671 \\ Editoras
}

\begin{abstract}
Atualmente, há um consenso entre os pesquisadores brasileiros de que os conhecimentos da Psicologia, enquanto ciência, bem como a prática profissional dos psicólogos não mais se restringem ao modelo clínico, centrado no atendimento individual, tampouco as explicações a respeito da constituição humana centram-se somente em aspectos intrapsíquicos (Tanamachi, 2002). Nas várias áreas em que o psicólogo atua, constata-se a discussão da importância de um trabalho social, em equipes multiprofissionais, utilizando referenciais teórico-metodológicos que busquem responder, de alguma maneira, aos desafios postos pela realidade social na qual os indivíduos estão inseridos, destacando-se sua constituição histórica e cultural ${ }^{4}$.

No campo da Psicologia Escolar e Educacional, os pesquisadores da área propõem uma formação profissional de psicólogos centrada no pensamento e prática críticos, capaz de analisar as transformações vigentes nos vários contextos educacionais e escolares, trabalhando coletivamente, a partir de uma perspectiva ético-política, utilizando referenciais que permitam a compreensão do fenômeno educativo na sua complexidade e considerando suas múltiplas determinações: sociais, políticas, institucionais e relacionais ${ }^{5}$. Para Asbahr, Martins e Mazzolini (2011), este novo modo de atuação do psicólogo em sua relação com a educação requer que os profissionais possam realizar uma ação que fuja à lógica patologizante e que ainda é tônica em muitos cursos de graduação. Assim, as autoras defendem uma formação em Psicologia que possibilite ao futuro psicólogo realizar intervenções apoiadas em inúmeros elementos que constituem a subjetividade e as relações escolares, a dinâmica institucional escolar, entre outros aspectos.

Atualmente, a formação de psicólogos no Brasil é regida pelas Diretrizes Curriculares Nacionais (DCN). Este conjunto de Diretrizes para o curso de Psicologia foi aprovado em 2004 (BRASIL, 2004) e revisado em 2011 (Brasil, 2011), fazendo com que as instituições de formação em nível superior tivessem que implementá-las, com todas as adequações e modificações que este novo modelo requer dos currículos e das estruturas de curso até então vigentes e centrados no Currículo Mínimo. Esse momento de implementação das novas Diretrizes coincidiu com a expansão de vagas no Ensino Superior, incrementada por uma nova política pública, instituída em nível federal e que privilegia a abertura de cursos e recursos para instituições privadas, conforme dados do MEC/INEP (2007). Em 15 de março de 2011 (BRASIL, 2011) foi instituída nova redação às Diretrizes Curriculares Nacionais para os cursos de graduação em Psicologia estabelecendo normas para a formação de professores de Psicologia. Esta atualização das DCN tem como objetivo contemplar um conjunto de conteúdos referentes à formação docente em Psicologia que, a partir desta nova regulamentação, deve ocorrer em um projeto pedagógico complementar de Licenciatura. Prevê uma carga horária além das previstas anteriormente acrescentando no mínimo 800 horas, com 500 horas de conteúdos específicos da área de Educação e 300 horas de estágio supervisionado (ABEP, 2014).
\end{abstract}

1 Universidade de São Paulo, São Paulo, Brasil.

2 Universidade Estadual de Maringá, Maringá, PR, Brasil.

3 Universidade Federal de Uberlândia, MG, Brasil.

4 Esta constatação pode ser verificada na produção recente da Psicologia, fruto de grupos de pesquisa no Brasil e de produções oriundas dos grupos de Trabalho da Associação Nacional de Pesquisa e Pós-Graduação em Psicologia ANPEPP.

5 O V Congresso Nacional Norte-Nordeste em Psicologia, realizado em Maceió, em 2007, organizou publicação intitulada "A produção na diversidade: compromissos éticos e políticos em Psicologia" que muito bem retrata parte das discussões recentes na área. 
Segundo as Diretrizes Curriculares Nacionais - DCNs para a área de Psicologia, o que se espera de uma formação profissional em Psicologia pelas Instituições de Ensino Superior do Brasil é que esteja voltada para a atuação profissional, pesquisa e ensino de Psicologia, assegurando determinados princípios e compromissos, a saber:

a) Construção e desenvolvimento do conhecimento científico em Psicologia; b) Compreensão dos múltiplos referenciais que buscam apreender a amplitude do fenômeno psicológico em suas interfaces com os fenômenos biológicos e sociais; c) Reconhecimento da diversidade de perspectivas necessárias para compreensão do ser humano e incentivo à interlocução com campos de conhecimento que permitam a apreensão da complexidade e multideterminação do fenômeno psicológico; d) Compreensão crítica dos fenômenos sociais, econômicos, culturais e políticos do País, fundamentais ao exercício da cidadania e da profissão; e) Atuação em diferentes contextos considerando as necessidades sociais, os direitos humanos, tendo em vista a promoção da qualidade de vida dos indivíduos, grupos, organizações e comunidades; f) Respeito à ética nas relações com clientes e usuários, com colegas, com o público e na produção e divulgação de pesquisas, trabalhos e informações na área da Psicologia, g) Aprimoramento e capacitação contínuos.

No que tange à atuação do psicólogo no campo da educação, as discussões, iniciadas nos anos 1980, tiveram excelentes resultados e muitos se articulam com as questões postas pelas novas Diretrizes Curriculares. A Psicologia Escolar e Educacional tem suscitado inúmeras reflexões acerca da formação e da prática dos profissionais que nela atuam; sobretudo, a necessidade de redefinição do papel do psicólogo na escola e de reestruturação de sua formação acadêmica, com dezenas de trabalhos publicados.

No âmbito das instituições políticas da Psicologia brasileira, com destaque para Associações, Sindicatos e o Conselho Federal de Psicologia, documentos importantes foram produzidos entre 2009 e 2013, quer voltados para a formação de psicólogos, quer centrados em áreas específicas de atuação profissional.

Um desses documentos foi divulgado pelo Conselho Federal de Psicologia, em 2012, fruto do Grupo de Trabalho Formação e intitulado "A Formação de psicólogas e psicólogos: respondendo às demandas da sociedade brasileira" (CFP, 2012), coordenado pela Profa. Dra. Ângela Caniato, Conselheira da Gestão 2010-2013 e Professora da Universidade Estadual de Maringá. Em um levantamento feito pelo GT foram encontrados 25 artigos sobre formação de psicólogos no Brasil e quatro livros sobre o tema, demonstrando a importância dessa discussão. Dentre importantes questões, o documento destaca a necessidade de construção de um projeto ético-político para a área de Psicologia que norteie os currículos dos cursos de formação profissional, chamando a atenção para determinados aspectos que precisam ser considerados quando se pensa em uma formação crítica em Psicologia, dentre eles o Documento destaca: a análise da conjuntura social, política, econômica para compreender o lugar da intervenção psicológica; a posição da área de Psicologia frente aos instrumentos que utilizamos para realizar determinado diagnóstico psicológico; a relação com a pesquisa e às demandas sociais postas à Psicologia e seu estatuto científico e a presença do ideário neoliberal nas políticas de formação em geral e do ensino superior que implantam modelos cada vez mais produtivistas e que se afastam das discussões de fundo das áreas em questão, no nosso caso, a Psicologia.

Além disto, no âmbito da formação em geral, em 2013, o CFP juntamente com a Associação Brasileira de Ensino de Psicologia e o Conselho Regional de São Paulo, produziram o documento intitulado "Carta de Serviços sobre Estágios e Serviços-escola", que institui diretrizes para a realização dos estágios e do funcionamento dos serviços-escola das instituições de ensino em Psicologia, no Brasil.

Visando aprimorar a formação de psicólogos na área da Educação Básica, estabeleceu-se nos anos de 2008 e 2009 uma articulação entre entidades da Psicologia ligadas à Educação, a Associação Brasileira de Psicologia Escolar e Educacional - ABRAPEE, a Associação Brasileira de Ensino de Psicologia - ABEP, os Conselhos Regionais de Psicologia do Brasil e o Conselho Federal para realizar o Ano Temático da Educação: Profissão na Construção da Educação para Todos. Esta articulação nacional produziu vários documentos discutindo a Psicologia em sua relação com a Educação incluindo um material intitulado Textos Geradores de discussão ${ }^{6}$; a Carta de Brasília e o Relatório do Seminário Nacional sobre o Ano Temático ${ }^{7}$, contando com a participação de 5.000 psicólogos em todo o país. O Documento dos Textos Geradores discutem temas que constituíram os Eixos Geradores de discussão do Ano Temático da Educação. São eles: Políticas Públicas Intersetoriais e Educação Inclusiva (Eixo temático 1 - autoria de Cristina Maria Carvalho Delou), Políticas Educacionais: legislação, formação profissional e participação democrática (Eixo temático 2 - autoria de Marilene Proença Rebello de Souza e Marisa Lopes da Rocha), Psicologia em Instituições Escolares e Educacionais (Eixo temático 3 - autoria de Raquel Souza Lobo Guzzo), e Psicologia no Ensino Médio (Eixo temático 4 - autoria de Ângela Fátima Soligo e Roberta Gurgel Azzi) (CFP, 2009). Em 2010, foi produzido um Documento, com base nas Diretrizes obtidas pela discussão do Ano Temático da Educação do Sistema Conselhos de Psicologia intitulado "Contribuições da

6 Documento disponível no endereço http://www.crprj.org.br/publicacoes/cartilhas/ano-educacao.pdf

7 Este Documento encontra-se disponível no endereço http://www.crprj.org.br/publicacoes/relatorios/seminario-educacao.pdf 
Psicologia para a CONAE", primeira Conferência Nacional de Educação, distribuído amplamente aos Delegados da Conferência e disponibilizado pelo sítio eletrônico http://site.cfp.org.br/wp-content/uploads/2010/03/cartilha-CONAE-web_x2x.pdf

As discussões no campo da Educação Básica geraram importante documento construído pelo CREPOP_ Centro de Referências Técnicas em Psicologia e Políticas Públicas ${ }^{8}, 2013$ intitulado "Referências Técnicas para a Atuação de Psicólogas(os) na Educação Básica". Como o título indica, o documento é composto por um conjunto de diretrizes ético-políticas para a atuação de psicólogos na Educação Básica visando a emancipação humana.

As recentes publicações no campo da Psicologia Escolar têm demonstrado que a complexidade das novas diretrizes revela a necessidade de mudanças nas concepções quanto à estrutura do curso, ao perfil profissional dos egressos desejados e à maneira de estabelecer relações significativas entre teoria e prática no contexto curricular e da ação pedagógica. Em 2007, o Grupo de Trabalho em Psicologia Escolar e Educacional da ANPEPP organizou publicação intitulada "Formação em Psicologia Escolar: realidades e perspectivas", coordenada pelo Prof. Dr. Herculano Ricardo Campos (Campos, 2007), cujos capítulos se remetem a esse importante momento da formação.

Portanto, o movimento de crítica à formação profissional, visando seu aprimoramento, é uma constante nas pesquisas e discussões nas associações, entidades de classe e representativas dos vários segmentos da Psicologia Brasileira. A constituição do Fórum das Entidades Nacionais da Psicologia Brasileira, em 2001, do qual fazem parte 26 entidades nacionais, das diversas áreas da Psicologia no Brasil, demonstra esta condição de participação ativa na formação profissional de psicólogos no Brasil.

Em 2017, um novo impulso às discussões sobre a formação profissional se fez presente, mediante solicitação do Conselho Nacional de Saúde para as profissões de saúde atualizarem suas DCNs. A Psicologia brasileira se organizou de maneira a ampliar ao máximo a participação dos cursos de Psicologia, dos professores, coordenadores, pesquisadores e estudantes que puderam propor sugestões para a melhoria das Diretrizes Curriculares Nacionais em Psicologia, com a organização de eventos em todo o país, coordenados pelo Conselho Federal de Psicologia - CFP, pela Associação Brasileira de Ensino de Psicologia - ABEP e pela Federação Nacional de Sindicatos de Psicólogos - FENAPSI. Se a busca pela qualidade na formação, pela inserção de psicólogos em políticas públicas, por uma formação generalista, pelo compromisso com os princípios ético-políticos e científicos foram as principais marcas da formação de psicólogas(os) no Brasil, consideramos que as discussões desencadeadas para o aperfeiçoamento das DCNs muito contribuirão para tal finalidade.

A Psicologia Escolar e Educacional continuará participando ativamente de todos os momentos e ações desse importante processo de aperfeiçoamento do texto legal das DCNs, destacando e defendendo a importância social e acadêmica da Psicologia no campo da Educação Básica e Superior. Defendemos que a Educação deva ser sempre um tema fundamental na sociedade, visando enfrentar a desigualdade social, o preconceito contra pobres, negros, indígenas, quilombolas, questões de gênero e deficiências. Sua presença deve se fazer nas políticas públicas educacionais que visem os direitos humanos, o desenvolvimento humano e a aprendizagem em sua plenitude, para que possamos atingir, cada vez mais, as mudanças sociais necessárias a uma sociedade mais justa e de qualidade social.

\section{Referências}

Asbahr, F. S. F.; Martins, E.; Mazzolini, B. P. M. (2011). Psicologia, formação de psicólogos e a escola: desafios contemporâneos. Psicol. estud. vol.16 n.1 Maringá.

Associação Brasileira de Ensino em Psicologia (ABEP). Diretrizes Curriculares. Acesso: 15 jan. 2014. Disponível: <http://www. abepsi.org.br/site/temas-e-debates/diretrizes-curriculares/>.

Brasil. Ministério da Educação, Conselho Nacional de Educação/ Câmara de Educação Superior (2004). Parecer 0062/2004, aprovado em 19/02/2004, fixa as Diretrizes Curriculares Nacionais para os cursos de graduação em Psicologia. Brasília.

Brasil. Ministério da Educação, Conselho Nacional de Educação/ Câmara de Educação Superior. (2011). Resolução CNE N 5/2011, aprovado em 15/03/2011, fixa as Diretrizes Curriculares Nacionais para os cursos de graduação em Psicologia. Brasília.

8 Documento disponível no endereço http://crepop.pol.org.br/novo/wp-content/uploads/2013/04/MIOLO_EDUCACAO.pdf 
Campos, H. R. (Org). (2007). Formação em Psicologia Escolar. realidades e perspectivas. Campinas, Alínea.

Tanamachi, E.R. (2002). Mediações teórico-práticas de uma visão crítica em Psicologia Escolar. In: Tanamachi, E.R., Proença, M., Rocha, M. (Orgs.). Psicologia e Educação: Desafios teórico-práticos. (pp. 73-104). São Paulo: Casa do Psicólogo.

\section{Sobre as autoras}

Silvia Maria Cintra da Silva (silvia@ufu.br)

Psicóloga, Mestre e Doutora em Educação, Docente Associado IV do Instituto de Psicologia da Universidade Federal de Uberlândia. Presidente Anterior da ABRAPEE. Editora da Revista Psicologia Escolar e Educacional.

Marilda Gonçalves Dias Facci (marildafacci@gmail.com)

Psicóloga, Mestre em Educação, Doutora em Educação Escolar com pós-doutorado em Psicologia Escolar e do Desenvolvimento Humano e também em Educação. É professora do Departamento de Psicologia e Programa de Pós-Graduação em Psicologia da Universidade Estadual de Maringá. Primeira Secretária da ABRAPEE. Editora da Revista Psicologia Escolar e Educacional e também Psicologia em Estudo. Coordena o GT de Psicologia e Políticas Educacionais da Associação Nacional de Pesquisa e Pós-Graduação em Psicologia - ANPEPP.

Marilene Proença Rebello de Souza (marileneproenca@gmail.com)

Psicóloga, Mestre, Doutora e Livre-Docente em Psicologia Escolar e do Desenvolvimento Humano. Professora Titular da Universidade de São Paulo. Diretora do Instituto de Psicologia da USP (2016-2020). Presidente Atual da ABRAPEE. Editora da Revista Psicologia Escolar e Educacional. unrestricted use, distribution and reproduction in any medium, provided the original article is properly cited. 